8-10-2017

\title{
Every Word, Every Gesture
}

\section{Dennis J. Baumgardner}

Follow this and additional works at: https://aah.org/jpcrr

Part of the Bioethics and Medical Ethics Commons, Medical Education Commons, Medical Humanities Commons, Primary Care Commons, and the Psychological Phenomena and Processes Commons

\section{Recommended Citation}

Baumgardner DJ. Every word, every gesture. J Patient Cent Res Rev. 2017;4:136-8. doi: 10.17294/ 2330-0698.1258

Published quarterly by Midwest-based health system Advocate Aurora Health and indexed in PubMed Central, the Journal of Patient-Centered Research and Reviews (JPCRR) is an open access, peer-reviewed medical journal focused on disseminating scholarly works devoted to improving patient-centered care practices, health outcomes, and the patient experience. 


\title{
PATIENT-CENTERED ESSAY
}

\section{Every Word, Every Gesture}

\author{
Dennis J. Baumgardner, MD
}

Department of Family Medicine, Aurora University of Wisconsin Medical Group, Aurora Health Care, Milwaukee, WI

$\mathrm{T}$ hirty-five years ago, I took the requisite patient interviewing and social-medical courses in medical school. Even then, the importance of a background in humanities, the process of ethical reflection and the personal connection of the patient interview were emphasized. ${ }^{1,2}$ Like most novice clinicians entering clinical rotations, I was ill-prepared for the practice, mutual impact and profound power of personal encounters with patients.

Although it took years for me to appreciate the full impact of these "professional" relationships, two patients whom I encountered very early in my clinical practice taught me some of my most enduring lessons. I share these stories in the hope they may provide others similar enlightenment.

\section{Silent Treatment}

The nurses told me he couldn't talk.

Mr. C was a middle-aged man, a nursing home resident with long-standing hydrocephalus whom I was caring for as a medical student on inpatient service. I had been given a vague history that his condition had potentially been neglected for some time in the past, leading to further deterioration of his functional abilities. He was cognitively handicapped and a "brittle" diabetic maintained on an unusual insulin regimen.

Every morning during my rounds, I would greet him with, "Hi, Mr. C, how are you doing?" then busy myself with checking him over and making small talk, to which he never responded. Still, every visit I would explain to

Correspondence: Dennis J. Baumgardner, MD,

Aurora Sinai Medical Center, 1020 N. 12th Street, \#4180,

Milwaukee, WI, 53233, T: +1-414-219-5191,

Email: dennis.baumgardner@aurora.org him what was going on with his health and what we were trying to do. These encounters went on for several days.

One night while on call in the hospital, I was paged by Mr. C's nurse regarding an episode of hypoglycemia. His blood sugar was disconcertingly low, but not critical. Going to his bedside, I noted that he remained alert and able to follow simple commands. Intravenous access was usually impossible, and this night was no exception, so we scrambled to find something to safely feed him that he would accept. We hit on ice cream, and for the next two hours I spoon-fed him at his bedside while the nurse checked his blood sugar at frequent intervals until he was stable.

While I was a little bit sleepy, Mr. C was thoroughly enjoying himself. He had never smiled like that or been animated at any time during our previous encounters. Several times that night, he looked right at me and gave me a great big smile. In many ways we were worlds apart; but I felt a bond with him, a genuine and personal human bond.

A morning or two later, I entered his room and proffered my standard greeting: "Hi, Mr. C, how are you doing?" Anticipating no response, I began his examination. "Not too good" was his slow, growly retort. I could not believe it; I almost keeled over. They said he didn't talk! Well, he did talk, and he continued to converse a bit more and for longer intervals each day going forward, even though his physical status remained otherwise unchanged. To this day I have no idea why he started talking, but I will always feel that our 2 a.m. ice creamfest had much to do with it.

My initial reflections on this case, other than the rather unexpected personal reward I felt from connecting with this patient, were superficial. I did get the sense that I should never stop attempting to communicate with 
a patient. Clearly, despite the struggles some face in relating to minimally conscious patients, ${ }^{3} \mathrm{I}$ realized it was perhaps possible to relate to any patient regardless of the perceived barriers. I also understood that I had a lot to learn about effective communication with patients with disabilities ${ }^{4}$ (the specifics of which are beyond the scope of this essay).

Only much later did I come to realize that my experience with this gentleman went far beyond such technical matters. It was a lesson in the inherent dignity of each patient, regardless of circumstances, and in all patients' potential to positively influence all those around them, including me.

\section{Emotions Far From Paralyzed}

The second encounter occurred when I was an intern at an urban hospital. One of the patients I had assumed care for was Mr. S, a man in his fifties who had been stricken with Guillain-Barré syndrome. He was nearly completely paralyzed, on a ventilator and essentially noncommunicative. After weeks of ICU care without improvement, he was moved to a regular hospital room.

Mr. S was nutritionally very poor. Several attempts at central line maintenance and hyperalimentation had failed due to blood stream infections, recurrent aspiration and intractable diarrhea. He could tolerate no more than $60 \mathrm{~mL}$ per hour of enteral feeding and was markedly edematous in all extremities. For this reason, maintenance of intravenous access had progressed from difficult to impossible. Previously, at a time when he was more communicative, the decision had been made to avoid further ICU care or treatment with central lines.

I saw him nearly every day during my two-month rotation. All of us caregivers did our best to keep Mr. $\mathrm{S}$ stable and comfortable despite being limited to liquid and intramuscular medications and supplements. During his daily examinations, I always greeted him by name and would briefly describe anything new we were doing and why. Sometimes I would talk about the weather or an item on the news. It was nothing special - my time was usually limited by a heavy patient load. He would listen impassively, his face puffy and mostly paralyzed. During the time I was with him, I never saw any family or friends visit him.
At the end of the rotation, I was convinced I had made no personal impact on this patient whatsoever. Following my examination, I faced him and explained that this was my last day on service and that I would no longer be taking care of him. I mentioned the new resident's name and expressed that it had been a pleasure to care for him. When I looked into his eyes, they were streaming with tears. I was completely taken aback.

Several days later, I received a page while working at another hospital indicating that Mr. S had died. I knew that it was a blessing for him in some ways. But I also felt a sense that I had lost a great teacher, although I could not completely comprehend in what way.

\section{Can Empathy Be Taught?}

In the decades following these two experiences, I eventually learned that the clinician-patient relationship, even if based on a single encounter, can be therapeutic. ${ }^{5}$ As Donald Sessions put it, "connection even for a brief moment produces the powerful enchantment of presence for patients and physicians;" ${ }^{2}$ however, achieving such a connection seems to require the willingness to see the person behind the patient. This requires empathy - a quality Seamus O'Mahony states "cannot be taught"1 — in addition to compassion. Fernando and Considine wrote that compassion "involves empathy, but includes the additional step of wanting to help and/or desiring to relieve the suffering of others;" and they concluded that "the capacity for compassion appears to be hardwired among humans."

For at least a century there has been tension within societies between "population-based medical prioritization" and compassionate individual care of a patient, sometimes to an unfortunate extreme. ${ }^{7}$ In light of this dichotomy, the concept of "hardwired compassion"6 is a hopeful one. Under this concept, it is thought that care, in the sense of compassionate regard for the dignity and well-being of the patient, trumps technological management.

But is it always true that empathy and compassion cannot be taught? Perhaps patients have the power to teach these virtues. Petra Gelhaus stressed that compassionate care is "an attitude as well as an activity." Clinician attitudes can be changed with interventions, which can include empathy-building tasks. ${ }^{9}$ Individual patient encounters can serve as 
interventions when one is open to, and reflective upon, the relational aspects of the encounter.

These two patients taught me that simply caring about them enough to make attempts to relate to them as people was meaningful. I learned that "activity" may be simply giving your time and presence. As film producer Martin Gabel was fond of instructing flailing actors: "Don't just do something; stand there." When you care, you wish to give. What you can give is your time and concern. To me, these patient encounters were lessons in compassion.

Medical technology is sometimes futile. Never futile are your best attempts at compassionate care for your patient. Every word, every gesture can have an impact — on both patient and physician.

\section{Acknowledgment}

In addition to the two patients described herein, the author thanks John J. Frey, III, MD, of the University of Wisconsin School of Medicine and Public Health (Madison, WI) for his encouragement to write.

\section{Conflicts of Interest}

None.

\section{References}

1. O'Mahony S. Against narrative medicine. Perspect Biol Med. 2013;56:611-9. CrossRef

2. Sessions DG. Making a personal connection in the medical interview. Mo Med. 2009;106:188-90.

3. Berry PA. The absence of sadness: darker reflections on the doctorpatient relationship. J Med Ethics. 2007;33:266-8. CrossRef

4. Iezzoni LI, Long-Bellil LM. Training physicians about caring for persons with disabilities: "Nothing about us without us!" Disabil Health J. 2012;5:136-9. CrossRef

5. Ornstein PH. The family physician as a "therapeutic instrument". J Fam Pract. 1977;4:659-61.

6. Fernando AT 3rd, Consedine NS. Beyond compassion fatigue: the transactional model of physician compassion. J Pain Symptom Manage. 2014;48:289-98. CrossRef

7. Reich WT. The care-based ethic of Nazi medicine and the moral importance of what we care about. Am J Bioeth. 2001;1(1):64-74. $\underline{\text { CrossRef }}$

8. Gelhaus P. The desired normal attitude of the physician: (III) care. Med Health Care Philos. 2013;16:125-39. CrossRef

9. Samra R, Griffiths A, Cox T, Conroy S, Knight A. Changes in medical student and doctor attitudes toward older adults after an intervention: a systematic review. J Am Geriatr Soc. 2013;61:1188-96. CrossRef

(C) 2017 Aurora Health Care, Inc. 